\title{
WENCESLAU DE MORAES, INTÉRPRETE DA CULTURA JAPONESA
}

\section{Claudio Alexandre Barros Teixeira*}

Universidade Federal de Minas Gerais

\begin{abstract}
Resumo: No presente artigo, comentaremos a recepção crítica e criativa da poesia japonesa na obra do escritor, diplomata e militar português Wenceslau Moraes, que foi o primeiro tradutor do haicai japonês para a língua portuguesa. O autor adotou a forma da quadra poética em redondilhas para a transcriação dos tercetos japoneses e valorizou os trocadilhos, paronomásias, expressões populares e outros elementos de função poética presentes no haicai tradicional, além de comentar aspectos da arte poética, filosofia, religião, estética e da língua japonesa, a partir dos princípios filosóficos do xintoísmo e do budismo zen. Suas obras completas, que reúnem ensaios, cartas, diários e relatos de viagens, incluem 14 volumes dedicados ao Japão e à cultura japonesa, entre os quais se destaca Relance da alma japonesa, publicado em 1925, no qual aborda desde a poesia tradicional de corte, reunida nas antologias palacianas, publicadas a partir do século VIII d.C., até o haicai clássico e as canções e provérbios populares.
\end{abstract}

Palavras-chave: Haicai. Tanka. Ideograma

Wenceslau de Moraes (1854-1929), oficial da marinha, diplomata e escritor português, pesquisou a história, religião, folclore, política, literatura e artes tradicionais japonesas e publicou diversos livros sobre esse repertório cultural, entre eles Dai-nippon (1897), Cartas do Japão (1904), O culto do chá (1905), Relance da história do Japão (1924) e Relance da alma japonesa (1926). "Em seus vários livros”, escreve Paulo Franchetti,

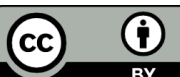

Esta obra está licenciada sob uma Creative Commons - Atribuição 4.0

\footnotetext{
* Doutor em Literatura Portuguesa pela Universidade de São Paulo (USP). Realizou o mestrado na mesma universidade. Graduou-se em Jornalismo pela Faculdade de Comunicação Social Cásper Líbero. Colunista da revista CULT e editor da Zunái, Revista de Poesia \& Debates (www.zunai.com.br), ocupou entre 2010 e 2014 o cargo de curador de literatura e poesia do Centro Cultural São Paulo. Entre 2013 e 2014, lecionou Literatura Portuguesa na UNIP. Foi um dos curadores do Festival Tordesilhas - Poetas de Língua Portuguesa, realizado em 2010, em Lisboa. Publicou diversos livros de poesia com o pseudônimo de Claudio Daniel, entre eles A sombra do leopardo, Figuras metálicas, Fera bifronte e cores para cegos. Publicou volumes de tradução de poesia latino-americana, entre eles Jardim de camaleões - A poesia neobarroca na América Latina e organizou a antologia Ovi Sungo: Treze poetas de Angola, entre outras publicações. Ministra cursos livres de teoria e criação literária na Casa das Rosas, Casa Guilherme de Almeida, Academia Internacional de Cinema, Biblioteca Alceu Amoroso Lima e no Laboratório de Criação Poética, entre outras instituições. Realiza atualmente pesquisa de pós-doutoramento em Teoria Literária pela Universidade Federal de Minas Gerais (UFMG). E-mail: claudio.dan@gmail.com
} 
"Wenceslau de Moraes [...] relata costumes típicos, traduz haicai, comenta a literatura, a arte e a história do Japão, tenta incentivar o comércio e a compreensão entre as suas duas pátrias" (FRANCHETTI, 2012, p. 38). Ao contrário de outros viajantes europeus, que descreveram a cultura japonesa sob um olhar preconceituoso e racista, "Moraes se esforça por mostrar aos portugueses a grande e sofisticada civilização que se desenvolvia no outro extremo do mundo" (idem). O escritor português, que como oficial da marinha e diplomata conheceu Moçambique, Macau, Timor Leste e as ilhas japonesas, não adota uma visão generalista sobre o "Oriente", preocupando-se, ao contrário, em perceber a especificidade do traço cultural japonês, respeitando seus usos e costumes, inclusive adotando suas vestimentas, idioma e hábitos alimentares. $\mathrm{O}$ escritor converte-se ao zen-budismo, casa com uma japonesa e passa os seus últimos anos em Tokushima, mergulhado no estudo de uma cultura que o encanta. No presente artigo, iremos comentar a recepção da poesia japonesa na obra de Moraes, que foi o primeiro tradutor do haicai para a língua portuguesa.

Em Relance da alma japonesa, volume publicado em 1926, Moraes "fez uma apresentação do haicai que fugiu por completo ao registro do exotismo pitoresco" (FRANCHETTI, 2012, p. 38), abordando a estrutura da língua japonesa, normas gramaticais, gêneros poéticos e recursos estilísticos de uma literatura que, até então, era quase desconhecida em Portugal. Sobre a escrita japonesa, escreve o autor:

\footnotetext{
Na língua japonesa, quando escrita (ou pintada, porque o pincel substitui a pena), as palavras escrevem-se de cima para baixo e da direita para a esquerda, ao contrário do que sucede com as línguas européias; empregando símbolos gráficos, silábicos, que os japoneses inventaram, ou então os caracteres ideográficos [...]. Desse processo de escrever, deriva o fato de que a primeira página de um livro japonês corresponde à última de um livro escrito a nossa moda. (MORAES, 1926, p. 30)
}

Wenceslau de Moraes, atento à relação entre poesia, caligrafia e pintura, destaca os materiais utilizados na escrita (o pincel, a pena), a diferença entre os sinais gráficos que representam sons e os caracteres ideográficos, que são figuras abreviadas, bem como a peculiar forma de leitura da escrita japonesa, tão diversa da conhecida nas línguas ocidentais. O autor observa a relação íntima entre as regras gramaticais e os conceitos filosóficos que moldaram a cultura japonesa com percepção acurada:

\footnotetext{
Na gramática japonesa, não há artigos; os substantivos e adjetivos são invariáveis, independentes de gênero e de número; quase que não há pronomes pessoais; os tempos dos verbos são invariáveis, independentes de pessoas; não há sujeito gramatical na oração; de sorte que os fenômenos passam-se como que num mundo sem espectadores, sem testemunhas dos fatos, visto que os indivíduos se eliminam propositadamente da cena; estranha coisa, que leva à compreensão da impersonalidade japonesa. (MORAES, 1926, p., 211).
} 
A diferença entre a lógica gramatical do idioma de Bashô e sua equivalente na língua de Camões não é considerada por Moraes como deficiência ou falha, e sim como reflexo, no mundo das palavras, de conceitos espirituais: "Começamos a adivinhar aqui um conceito da mais alta importância psíquica, na mentalidade do nipônico: a impersonalidade humana, perante os fenômenos da vida" (MORAES, 1926, p. 35). O agente individual, numa cultura regida pelos princípios de Confúcio e Hui-neng - sexto patriarca do zen budismo chinês -, é algo "de somenos importância, em presença do grandioso drama da natureza criadora" (idem).

Prossegue o autor:

\begin{abstract}
$\mathrm{Na}$ língua japonesa, se excetuarmos um ou dois termos raramente empregados, que designam a primeira pessoa, pode dizer-se que não há pronomes pessoais. A consequência imediata deste curiosíssimo fenômeno filológico é não haver senão uma palavra para cada modo e tempo de cada verbo. [...] Na conjugação dos verbos japoneses, não se tem em conta as pessoas. [...] Estabelecida claramente esta distinção, pode e deve-se dizer que não existe sujeito gramatical em japonês. Com efeito, ficou notado que a noção de pessoa, isto é, de um ser subsistente e potencial, não existe nesta língua. A consequência rigorosa deste fato é a impersonalidade absoluta no verbo, o qual não exprime mais do que a existência de um acontecimento, de um estado ou de uma paixão, sem relação com a pessoa. (MORAES, 1926, p. 38)
\end{abstract}

A impessoalidade, ou ausência de um eu separado do campo dos fenômenos é um conceito caro à doutrina budista. Conforme explica Ricardo M. Gonçalves em seu livro Textos budistas e zen-budistas, "neste contínuo vir a ser que é este mundo, nada existe de substancial e definitivo. Nenhum fenômeno existe independentemente do contexto em que ele se situa, e seu destino é transformar-se, quando o contexto se modifica" (GONÇALVES, 1995, p. 15). A ausência de um eu, nesta filosofia tão diferente do pensamento religioso cristão e mesmo das doutrinas devocionais do Extremo Oriente, fundadas na dualidade entre o eu e o outro, o divino e o humano, o sujeito e o objeto, está relacionada a outro princípio da metafísica budista, o da interdependência. Segundo Ricardo M. Gonçalves,

as coisas não se definem pelo que elas são em si, mas pela rede de condicionamentos e relacionamentos que as ligam ao contexto. $\mathrm{O}$ homem, ao se analisar, não encontra em si mesmo e ao seu redor nada a que possa se apegar como sendo seu eu, sua personalidade substancial (MORAES, 1926, p. 15).

A consequência deste pensamento é que o mundo dos fenômenos, sendo vazio de substancialidade e em contínuo processo de transformação, é impermanente: tudo muda o tempo todo, logo, os seres e as coisas não têm realidade estável, fora de situações específicas do espaço e do tempo, daí a analogia com a experiência do sonho. O único Absoluto, conforme a metafísica budista, é o Vazio, ou Sunyata, que é "inacessível ao pensamento e à 
linguagem" e que "está em todas as coisas e também dentro delas" (idem, 13). Este Vazio "é o Uno, a Totalidade de Existência, o Absoluto, mas pode revelar a si mesmo através da multiplicidade dos fenômenos relativos, contingentes e transitórios, assim como a luz só se revela como tal quando incide em corpos opacos que provoquem o contraste luz-trevas" (idem). A arte tradicional japonesa, que expressa este pensamento filosófico, oculta o eu desde a estrutura da língua, ao mesmo tempo em que privilegia a representação do vazio, seja nas pinturas a nanquim, seja na arte da caligrafia, na jardinagem ou na arquitetura. Quando os jesuítas portugueses e espanhóis iniciaram sua missão evangelizadora na Terra do Sol Nascente, foi inevitável o confronto entre a concepção dualista da realidade, que considera Deus, homem e mundo como realidades distintas, eternas e inconfundíveis, e o pensamento monista do budismo japonês.

Paulo Leminski, comentando o encontro do missionário espanhol Francisco Xavier com o bonzo Ninshitsu, escreve:

\footnotetext{
Xavier fala do amigo: "tenho falado com diversos bonzos ilustrados, especialmente com um que é tido na mais alta estima por todos, pelo seu saber, conduta e dignidade, como pela avançada idade de oitenta anos. Seu nome é Ninshitsu, que em japonês significa 'Coração da Verdade'. É uma espécie de bispo entre eles e, se o nome que usa é apropriado, é realmente um homem abençoado... Esse homem tem sido para mim um amigo maravilhoso".

O diálogo entre eles, porém, não deve ter sido muito fácil.

Xavier ficou confuso, logo de cara, ao conversar com Nishitsu.

O velho mestre zen parecia não saber se "possuía" ou não uma alma. Para ele, era inteiramente estranho o conceito de que "uma alma" era uma espécie de objeto que "alguém" pode estar "possuindo" e até mesmo "salvando". (LEMINSKI, 1983, p. 77)
}

Os jesuítas ficaram confusos com a sensibilidade religiosa japonesa, com a sua concepção do sagrado, com o seu modo de vivenciar a espiritualidade na relação harmoniosa com a natureza, nas práticas artísticas e sobretudo com o seu sincretismo, tão diverso da exigência de exclusividade da religião católica, do islamismo e do judaísmo. Na sociedade japonesa, como observou Wenceslau de Moraes, o budismo, o confucionismo e o xintoísmo conviviam sem grandes conflitos: para um japonês, era comum seguir os preceitos confucionistas em suas relações com a família, o professor, o patrão, o senhor feudal, o imperador, participar das festividades populares xintoístas e adotar o budismo como veículo para a iluminação. Conforme Wenceslau de Moraes,

A doutrina filosófica de Confúcio fora conhecida no Japão muitos anos atrás; mas não criara escola, adormecia, para acordar muito mais tarde, formando adeptos. $\mathrm{O}$ 
budismo, em face do xintoísmo, com este facilmente cooperou, impressionando as massas pelas suas belas aparências rituais e pelas consolações que lhe trazia. Os japoneses encontraram nele aquilo de que o seu espírito carecia, isto é, a afirmação de uma vida eterna após metempsicoses sucessivas; o prêmio da virtude, o castigo da maldade, um paraíso e um inferno, preceitos de piedade a exercer para com os homens e para com os animais, o amor da paz e mil outros dogmas benfazejos. $\mathrm{O}$ budismo pregava-lhes a inconsistência de todas as coisas deste mundo - dos prazeres, dos regalos, da luxúria, dos desejos, das paixões, do amor - chamando-os ao recolhimento, à contemplação exclusiva da divindade e das coisas divinas. $\mathrm{O}$ apelo à abnegação, à simplicidade, calhava bem com a noção íntima que os japoneses nutriam de si próprios, da sua própria impersonalidade; e seguramente a reforçava. Nenhuma outra religião viria mais de molde, como veio o budismo, a colaborar com o xintoísmo, posto que tão diferente dele. O povo abraçou as duas crenças, como se fossem uma. (MORAES, 1926, p. 53-54)

Wenceslau de Moraes conhecia bem o repertório filosófico e religioso do Japão, em especial as práticas e princípios do zen-budismo, como percebemos na leitura de seus inúmeros livros sobre a cultura japonesa, como $O$ culto do chá, Fala a lenda japonesa e as Cartas do Extremo Oriente. Essa familiaridade ajudou o escritor português a entender a filosofia da arte que orienta a criação poética japonesa, em especial o tanka e o haicai, que ele "reimaginou" - para usarmos um termo caro a Haroldo de Campos, extraído de suas notas sobre a tradução de poemas chineses e japoneses - na forma das quadras portuguesas, sem rimas (a poesia tradicional japonesa, assim como a grega, não tinha rimas e os ideogramas eram dispostos em uma, duas, três ou quatro colunas). Conforme diz Wenceslau de Moraes:

Para estudiosos portugueses, todavia, o tanka e o hokku não devem merecer tanta
estranheza. Nós temos a quadra portuguesa, a nossa deliciosa quadra popular, tão
cheia de seduções que, uma só, pode constituir um poema emocionante. Dá-se
também a circunstância de serem certos processos de construção, de uso vulgar na
poesia japonesa, como o jogo de palavras, o calembur, ou então a reunião de dois
períodos, independentes um do outro no sentido, também vulgares na quadra
portuguesa. Em minha opinião, a nossa quadra, quando habilmente manejada, seria
suscetível de dar excelentes traduções dos poemas japoneses. (MORAES, 1926, p.
197)

Conhecida desde a Idade Média, a quadra popular era escrita em várias medidas métricas, especialmente a redondilha, também usada no haicai, e é uma das formas mais concentradas da poesia portuguesa. Sua aparente simplicidade, musicalidade e facilidade de memorização também permitem uma aproximação com o terceto japonês, assim como o emprego de palavras de uso cotidiano e jogos de palavras. Wenceslau de Moraes notou o uso recorrente de onomatopeias na poesia japonesa, como "bisho-bisho (ideia de molhar, de alagar); bura-bura (preguiçosamente); chobo-chobo (gota a gota); goro-goro (estrondo de 
trovão) $^{1 "}$ (MORAES, 1926, p. 30). O autor percebeu, com olhar acurado, a ocorrência, no haicai, da "reunião de dois períodos, independentes um do outro no sentido, também vulgares na quadra", que sendo "habilmente manejada, seria suscetível de dar excelentes traduções dos poemas japoneses" (MORAES, 1926, p. 30). A partir dessa minuciosa investigação da estética do haicai, Wenceslau de Moraes realiza a transcrição do poema japonês para a quadra - e recordemos aqui o emprego da palavra transcrição por Guilherme de Almeida, no artigo Ritmo, elemento de expressão, em que o poeta e tradutor brasileiro usa o termo tal como é entendido na teoria musical, ou seja, "escrever para um instrumento música escrita para outro" (ALMEIDA, 1997, p. 17). A comparação entre a atividade tradutória e a transcrição de partituras na música erudita, aliás, recorda uma outra comparação feita por Roman Jakobson em conferência pronunciada em 1967, em Tóquio: "Pode-se mesmo dizer que uma tradução fiel, cerrada, de poesia seja uma contradição em termos. O que permanece passível é a transposição congenial - a resposta livre, criativa, de um poeta de língua inglesa a um autor russo ou japonês e vive-versa", que o linguista soviético compara a "uma transposição inventiva, engenhosa, de um poema ou de um romance em pintura, cinema, balé ou numa composição musical" (CAMPOS, 1993, p. 7). A recriação dos haicais japoneses para o formato da quadra, portanto, pode ser considerada uma original releitura de Wenceslau de Moraes, e até uma antecipação das modernas teorias e práticas da tradução, como as desenvolvidas por Ezra Pound. O poema de Bashô sobre o salto da rã - o mais conhecido de todos os haicais - assumiu a seguinte fisionomia, ao ser transposto para a quadra portuguesa:

Furu-ike ya
Kawaza tobi-komu
Mizu no oto

Versão literal:

Ah, o velho tanque! e o ruído das rãs, atirando-se para a água!

Versão em quadra:

Um templo, um tanque musgoso;

Mudez, apenas cortada

Pelo ruído das rãs,

Saltando à água, mais nada... (MORAES, 1926, p. 198)

\footnotetext{
${ }^{1}$ Décio Pignatari usou a onomatopeia nas traduções que realizou de haicais de Kobayashi Issa, como nesta composição: "Lagos, pingos, tiros: / Quá-quá-quá dos patos patos / Por enquanto vivos”. (PIGNATARI, 1996, p. 79).
} 
A tradução literal da composição de Bashô recorda as versões que seriam feitas, nas décadas seguintes, por poetas tão distintos entre si como Paulo Leminski ("velha lagoa / o sapo salta / o som da água" "), Paulo Franchetti (“O velho tanque - Uma rã mergulha / Barulho de água")") e Casimiro de Brito ("No velho tanque / uma rã salta - mergulha. / Ruído na água $\left.{ }^{4,}\right)^{5}$, mas, na transcrição para a quadra, Wenceslau de Moraes afastou-se da síntese, da concisão e do estilo elíptico, abrupto, do haicai tradicional, buscando "explicar" o contexto do poema, sua atmosfera física e emocional, inserindo "palavras ou frases que não aparecem na versão literal”, como diz Paulo Franchetti. "O resultado, muitas vezes, deixa a desejar, porque o texto traduzido resulta muito explicativo ou mesmo prolixo ${ }^{6 \%}$. Assim, na versão do haicai para a quadra, Wenceslau de Moraes inclui um "templo" ausente no texto original, adjetiva o tanque como "musgoso", descreve o silêncio que é apenas implícito no poema ("Mudez, apenas cortada...") e acrescenta uma desnecessária ênfase no verso final (“mais nada...”). Podemos recordar o julgamento crítico de Haroldo de Campos a respeito das primeiras traduções de poemas chineses e japoneses, realizadas na década de 1920, consideradas pelo poeta e tradutor brasileiro como presas de um "exotismo edulcorado e fácil" (CAMPOS, 1993, p. 17), com uma tendência a "transmitir uma réplica aproximativa, vagamente simbolista, frequentemente diluída, do texto original" (CAMPOS, 1993, 15). A severidade do parecer, no entanto, pode ser exagerada, se aplicada a Wenceslau de Moraes (contemporâneo de Camilo Pessanha, Fernando Pessoa, Mário de Sá-Carneiro), que não era poeta e não teve como objetivo recuperar a informação estética dos textos originais, mas a sua informação semântica (usamos aqui as categorias de Max Bense), a partir de sua vivência no Império do Sol Nascente. $\mathrm{O}$ autor não ambicionou a "reconstituição da informação estética do original em português", contentando-se com "o simples escopo didático de servir de auxiliar à leitura desse original" (CAMPOS, 1978, p. 7).

Como bem observou Paulo Franchetti,

não é na discutível e interessante proposta de verter o haicai em uma forma tradicional portuguesa que reside o mérito maior de Moraes, e sim em ter enquadrado suas traduções em uma obra que fornece o que é mais raro em relação ao Extremo Oriente: uma visão de conjunto, harmônica e acurada (FRANCHETTI, 1990, p. 39).

\footnotetext{
${ }^{2}$ LEMINSKI, 1983, p. 20.

${ }^{3}$ FRANCHETTI, 2012, p. 81.

${ }^{4}$ BRITO, 1995, p. 13.

${ }^{5}$ R. H. Blyth assim traduz o mais conhecido de todos os haicais: "The old pond; / A frog jumps in, / The sound of the water" (BLYTH, 1981, p. 246, primeiro volume). Octavio Paz assim traduziu para o espanhol: "Un viejo estanque / salta uma rana zas! / Chapalateo" (PAZ, 1974, p. 241).

${ }^{6}$ FRANCHETTI, 1990, p. 39.
} 
que só foi possível porque o escritor possuía "um verdadeiro conhecimento dos aspectos mais importantes da cultura japonesa" (FRANCHETTI, 1990, p. 39). Na tradução de um haicai de Chiyo-Ni (1703-1775) ${ }^{7}$, Wenceslau de Moraes obtém o seguinte resultado:

\author{
Asagao $\mathrm{ni}$ \\ Tsurubê torarete \\ Moral mizu \\ A trepadeira trepou \\ Pela corda do pocinho; \\ Para não a molestar, \\ Vai pedir-se água ao vizinho. (MORAES, 1926, p. 200)
}

A resposta criativa do autor português à composição de Chiyo-Ni é opaca: o tradutor incluiu rimas (pocinho / vizinho) ausentes na poesia tradicional japonesa e intentou recuperar as sutilezas sonoras do original - de ritmo acentuado e com sugestivas assonâncias e aliterações - empregando uma paronomásia no verso inicial (a trepadeira trepou), que não reproduz o impacto fônico do texto de partida. A tradução conserva a linguagem coloquial, característica do haicai, mas o contorcionismo métrico e a estrutura rímica tornam o poema excessivamente artificial, distante da simplicidade almejada na arte japonesa, que valoriza a criação espontânea, a imperfeição e a assimetria, presentes na própria caligrafia. Em operação tradutória similar, Wenceslau de Moraes transpõe para a quadra um curiosíssimo poema, sem referência de autoria:

\author{
Nusundaru \\ Kagashi no kasa o \\ Amê kyu nari
}

Versão literal:

Cai duramente a chuva no chapéu que eu roubei ao espantalho ${ }^{8}$.

Versão em quadra:

Vai molhando até aos ossos;

Cai a chuva, mais e mais.

\footnotetext{
${ }^{7}$ No Brasil, Chiyo-Ni foi traduzida por Alice Ruiz, no livro Dez hai kais (Florianópolis: Editora Noa Noa, 1981), do qual destacamos este poema: "no pântano da montanha / nada se move / na manhã de neve" (RUIZ, 1981 p. 14).

${ }^{8}$ Wenceslau de Moraes apresenta um comentário à tradução, em que explicita sua dimensão referencial: "Quando o arroz está próximo da colheita, nuvens de pardais caem sobre o arrozal, na ânsia de devorar os bagos, maduros quase. $\mathrm{O}$ aldeão japonês fabrica então uns bonecos, uns espantalhos - e com que arte e graça! - veste-os com quimonos esfarrapados e inúteis, cobre-lhes as cabeças com chapéus de palha, da clássica forma piramidal, mas evidentemente podres à força de uso, não prestando para nada; e dispõe de espaço em espaço, no arrozal, alguns destes monstrengos, em trágicas posturas, a fim de espantarem os pardais. Para o nosso caso, devemos imaginar um pobre diabo qualquer, talvez um estudante pobre - e há tantos estudantes pobres no Japão!... - que fosse caminhando pela estrada, cabeça nua; surpreendido por um aguaceiro, arranca da cabeça de um espantalho o chapéu pobre, enfia-o na própria cabeça e continua o seu caminho, compondo, talvez, por passatempo, a poesia que citei”. (MORAES, 1926, p. 202)
} 
No chapéu, que foi roubar

No campo ao ‘spanta-pardais.” (MORAES, 1926, p. 202)

A versão literal, escrita em uma única linha, sem medidas métricas nem rimas, numa dicção seca, próxima à da prosa, tem objetividade e força expressiva; a imagem poética revela-se com precisão quase fotográfica. A recriação na forma da quadra, no entanto, revelase menos eficaz, pela inserção de palavras adicionais para manter a unidade métrica e o jogo de rimas (Cai a chuva, mais e mais) e pela torção sintática nas duas últimas linhas. Apesar do rebuscamento formal, a tradução apresenta algumas soluções interessantes, como a utilização de expressões da linguagem popular (molhando até aos ossos, 'spanta-pardais), recurso frequente nos haicais de Bashô, pouco afeito à fala palaciana. No décimo capítulo de seu livro Relances da alma japonesa, intitulado $A$ arte e a literatura, Wenceslau de Moraes traduz e comenta estes e inúmeros outros poemas japoneses, esmiuçando a dimensão referencial de cada peça, apresentando ao leitor aspectos da história, religião e cultura japonesas, numa linguagem simples e direta, sem debater aspectos técnicos ou linguísticos. Do ponto de vista poético, talvez as suas recriações mais interessantes sejam aquelas feitas em prosa, geralmente em uma única linha, sem preocupação artística; são textos curtos e diretos, que por isso mesmo traduzem de modo mais eficaz o espírito e a forma do haicai tradicional. Entre estas versões ${ }^{9}$, em que predomina a literalidade, destacamos a tradução do haicai de Yayô (17021783), poeta menos conhecido do cânone japonês:

\footnotetext{
Waré to waga

Kara ya tomurô,

- semi no kôe!
}

Cantando os ofícios fúnebres diante do seu próprio cadáver... - ai, a voz da cigarra!...

$(\text { MORAES, 1926, p. 105) })^{10}$

Os jogos aliterativos, nesta notável recriação (ofícios fúnebres), respondem de maneira criativa à tessitura sonora do texto original (Waré to waga), bem como a acentuação rítmica (próprio cadáver), e a súbita fratura operada na sentença, que passa de uma descrição para uma evocação, sugere o princípio da montagem na poesia japonesa tradicional.

\footnotetext{
${ }^{9}$ Outras traduções interessantes, sem identificação da autoria dos poemas: Furu terá ya / Kanê mono iwasu / Sakura chiru: Oh, o velho templo! o sino não toca; flores de cerejeira caem sobre o solo... e Yuki no mura / Niwa-tori naitê / Akê shiroshi: Aldeia coberta de neve; galos cantando; rompe a madrugada (MORAES, 1926, p. 200).

${ }^{10}$ Comentando a composição de Yayô, escreve Wenceslau de Moraes: "Basta isso, que é bem pouco, para vir sugerir ao pensamento do leitor uma impressão de delírio, profundamente perturbadora, só comparável àquelas que por vezes nos acodem, dormindo, durante um mau sonho, febril e angustioso; não logrando definir-se por completo no nosso espírito, porque faltam a este aptidões para senti-la; embora o perturbe como que a sensação do sopro frio de um ambiente extraterrestre, aonde houvéssemos mergulhado". (MORAES, 1926, p. 105).
} 
Wenceslau de Moraes, aliás, não se encantou apenas com a poesia clássica, mas também com a poesia popular, que comenta de modo bastante sucinto, relacionando-a com o canto, e com os provérbios tradicionais, que conservam o sabor enigmático e paradoxal das histórias zenbudistas. Provérbios populares ou sapienciais foram compilados na Bíblia, em textos religiosos indianos, poemas mitológicos escandinavos, relatos cosmogônicos quíchuas, clássicos chineses e diversas outras literaturas. Sua proximidade com a escrita poética - pela condensação frásica, tom misterioso, oracular, riqueza imagética e metafórica - foi observada por Wenceslau de Moraes, que conclui o seu capítulo sobre a arte e a literatura do Japão apresentando ao leitor uma lista comentada de provérbios, entre os quais destacamos os seguintes:

\section{Enkô ga tsuki wo toran to saru gagotoshi.}

(Como os macacos que quiseram apanhar a lua, refletida pelo próprio Buddha na água). Alude-se a uma parábola, contada pelo próprio Buddha, diz-se. Pela noite, alguns macacos, trepados sobre uma árvore, deram fé da imagem da lua, refletida na água de um poço. Oh, lá, a lua na terra, a descansar!... Resolveram sem demora apoderar-se dela. Um macaco enrola a cauda a um tronco de árvore; um segundo macaco agarra-se ao primeiro; um terceiro ao segundo; assim vão alongando a cadeia, até que o último macaco está quase a segurar a lua... Mas então o tronco da árvore verga e parte-se, mercê do grande peso que aguentava, e todos os macacos morreram afogados.

Gun-mô no taizô wo saguru go gotoshi.

(Como uma chusma de homens cegos, a apalpar um grande elefante). - Diz-se daqueles que ignorantemente criticam o budismo. Alude-se à célebre fábula acerca de alguns homens cegos que tentaram de decidir qual a forma do elefante, apalpando-o. Um apalpa a perna e declara que o elefante é semelhante a um tronco de árvore. Um outro, apalpando-lhe a tromba, declara-o semelhante a uma serpente. Um terceiro, apalpando-lhe a anca, diz que o elefante é igual a uma parede. Um quarto, apalpando-lhe a cauda, diz que o elefante é semelhante a uma corda...

(MORAES, 1926, p. 58-59)

Wenceslau de Moraes faz a versão literal dos provérbios japoneses, a partir do idioma nativo, acrescentando notas explicativas, com motivação referencial: é seu propósito familiarizar o leitor de língua portuguesa com as tradições religiosas, lendas e fábulas que inspiraram tais provérbios. Embora não enfatize a função poética, obtém, aqui e ali, resultados interessantes, pela precisão e objetividade, como este: Onna no ké ni wa daizô mo tsunagaru / "Com um fio de cabelo de mulher, até um grande elefante pode ser amarrado" (idem, 60). O escritor português conversa com a poesia e as tradições culturais japonesas com espírito receptivo, de quem deseja embebedar-se desse repertório e apresentá-lo de maneira direta e acessível à sua própria comunidade lingüística. 
O excepcional trabalho ensaístico e tradutório realizado por Wenceslau de Moraes no âmbito dos estudos da cultura japonesa só pode ser comparado ao efetuado por seu contemporâneo Camilo Pessanha (1867-1926) em relação à cultura chinesa, como a tradução das Oito elegias, os artigos e conferências que Daniel Pires reuniu no volume China - Estudos e traduções (Lisboa: Vega, 1993). A relação intelectual e de amizade entre os dois escritores, iniciada em 1885, na então colônia portuguesa de Macau ${ }^{11}$, onde o autor do Relance da alma japonesa se estabeleceu, antes de ir para o Japão, pode ser avaliada pelas dedicatórias que Pessanha oferece a Moraes na tradução da Terceira elegia (Sobre o terraço) e no poema Viola chinesa, que integra a Clepsidra. A possível correspondência entre eles, infelizmente, foi extraviada, assim como boa parte da produção tradutória de Pessanha, mas o poeta português manifestou seu apreço pelo amigo em artigo publicado no jornal A Pátria, em 7 de junho de 1924: "Notáveis prosadores (basta lembrar, dentre os contemporâneos, Lafcádio Hearn, Wenceslau de Moraes e Pierre Loti) têm celebrado condignamente os encantos dos países exóticos" (PESSANHA, 1993, p. 122). Após escrever 14 livros sobre o Japão, Wenceslau de Moraes falece em 1929, já afastado de suas funções diplomáticas e amargurado pela perda da companheira Ó-Yoné. Poucas de suas obras estão disponíveis nas livrarias portuguesas Cartas do Extremo Oriente (1993), Fala a lenda japonesa (1993), Fernão Mendes Pinto no Japão (1993), O culto do chá (1996), Ó-Yoné e Ko-Haru (2006), não havendo, até a presente data, uma edição crítica recente de suas obras completas, seja em Portugal ou no Brasil.

\section{Referências}

ALMEIDA, Guilherme de; VIEIRA, Trajano. Três tragédias gregas. São Paulo: Perspectiva, 1997.

BLYTH, R. H.. Haiku (quatro volumes). Tóquio: Hokuseido Press, 1981.

BRITO, Casimiro de. Poesia japonesa. Separata da Revista de poesia Limiar, Porto, n. 5, 1995.

CAMPOS, Haroldo de. Hagoromo de Zeami. São Paulo: Estação Liberdade, 1993.

Dante Aligheri - 6 cantos do Paraíso. São Paulo: Editora Fontada LTDA / Istituto

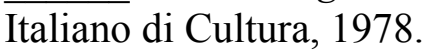

FRANCHETTI, Paulo; DOI, Elza Taeko. Haikai. Antologia e história. 2. ed. Campinas: Universidade Estadual de Campinas, 2012.

\footnotetext{
${ }^{11}$ Em sua edição da Clepsidra publicada em 2009 pela Ateliê Editorial, Paulo Franchetti inclui, na página 135 do volume, uma rara fotografia que registra o encontro de Wenceslau de Moraes com Camilo Pessanha em Hong Kong, em 1895.
} 
GONÇALVES, Ricardo M. Textos budistas e zen-budistas. São Paulo: Cultrix, 1995.

LEMINSKI, Paulo. Bashô, A lágrima do peixe. São Paulo: ed. Brasiliense, 1983.

MORAES, Wenceslau. Relance da alma japonesa. Lisboa: Parceria A. M. Pereira, 1926. .Fala a lenda japonesa. Lisboa: Cotovia, 1993. . Cartas do Extremo Oriente. Lisboa: Fundação Oriente, 1993. . Fernão Mendes Pinto no Japão. Lisboa: VEGA, 1993. . O culto do chá. Lisboa: Vega, 1996. 2006 . . Ó-Yoné e Ko-Haru. Lisboa: Instituto Camões / Imprensa Nacional - Casa da Moeda, PAZ, Octavio. Versiones y diversiones. Tabasco: Editorial Joaquín Mortiz, 1974.

PESSANHA, Camilo. Clepsidra. Organização, apresentação e notas de Paulo Franchetti. São Paulo: Ateliê Editorial, 2009. . China - Estudos e traduções. Lisboa: Vega, 1993.

PIGNATARI, Décio. 31 poetas, 214 poemas. São Paulo: Companhia das Letras, 1996.

RUIZ, Alice. Dez hai kais. Florianópolis: Editora Noa Noa, 1981.

[Recebido em setembro de 2015 e aceito para publicação em setembro de 2015]

\section{Wenceslau de Moraes, interpreter of japanese culture.}

Abstract: In this article we will comment on the critical and creative aspects of Japanese poetry in the work of Portuguese author and diplomat Wenceslau Moraes, who was the first translator of Japanese haiku into Portuguese. The author adopted the form of quatrain poem using lines of five or seven syllables for transcription of Japanese three line verses. Wenceslau valued puns, popular expressions and other elements of poetic function present in the traditional haiku. The author also commented on aspects of poetic art, philosophy, religion, aesthetics and Japanese language from the philosophical principles of Shinto and Buddhism. His complete works, in the form of essays, letters, diaries and travel reports, include 14 volumes dedicated to Japan and Japanese culture, with special attention to Relance da alma japonesa, published in 1925, a work that covers from tradition court poetry, collected from court anthologies published since the VIII Century a.D, to the classic haiku and popular songs and proverbs.

Keywords: Haiku, tanka, ideogram.

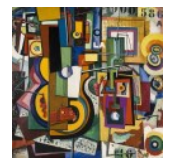

